\title{
Antisecretory Effect of Hydrogen Sulfide on Gastric Acid Secretion and the Involvement of Nitric Oxide
}

\author{
Seyyed Ali Mard, ${ }^{1}$ Hasan Askari, ${ }^{2,3}$ Niloofar Neisi, ${ }^{4}$ and Ali Veisi ${ }^{1}$ \\ ${ }^{1}$ Research Institute for Infectious Diseases of Digestive System, Physiology Research Center (PRC) and Department of Physiology, \\ The School of Medicine, Ahvaz Jundishapur University of Medical Sciences, Ahvaz 61357 15794, Iran \\ ${ }^{2}$ Department of Physiology, The School of Medicine, Tehran University of Medical Sciences, Tehran, Iran \\ ${ }^{3}$ Research Institute for Infectious Diseases of Digestive System, The School of Medicine, \\ Ahvaz Jundishapur University of Medical Sciences, Ahvaz 61357 15794, Iran \\ ${ }^{4}$ Research Institute for Infectious Diseases of Digestive System and Department of Virology, The School of Medicine, \\ Ahvaz Jundishapur University of Medical Sciences, Ahvaz 61357 15794, Iran \\ Correspondence should be addressed to Seyyed Ali Mard; mard-sa@ajums.ac.ir
}

Received 20 April 2013; Revised 24 December 2013; Accepted 8 January 2014; Published 24 February 2014

Academic Editor: David Bernardo Ordiz

Copyright (C) 2014 Seyyed Ali Mard et al. This is an open access article distributed under the Creative Commons Attribution License, which permits unrestricted use, distribution, and reproduction in any medium, provided the original work is properly cited.

\begin{abstract}
The present study was designed to investigate the effect of $\mathrm{H}_{2} \mathrm{~S}$ on distention-induced gastric acid secretion. Fifty-two rats were randomly assigned to seven experimental groups. The gastric acid secretion was stimulated by gastric distention. Two groups of rats received L-cysteine or saline for 5 days before stimulation of the gastric acid secretion. Two groups of animals also received NaHS or saline just prior to stimulation of the gastric acid secretion. The effect of L-NAME and propargylglycine was also investigated. The mucosal levels of the gene expression of cyclooxygenase-2 (COX-2), endothelial nitric oxide synthase (eNOS), and $\mathrm{H}^{+} / \mathrm{K}^{+}-\mathrm{ATPase}$ $\alpha$-subunit were quantified by qPCR and luminal concentrations of NO were determined. NaHS and L-cysteine decreased the gastric acid output in response to distention. The mRNA expression of $\mathrm{H}^{+} / \mathrm{K}^{+}$-ATPase $\alpha$-subunit decreased by NaHS and L-cysteine as compared with the control group while gene expression of eNOS and COX-2 was upregulated. The inhibitory effect of NaHS on distention-induced gastric acid secretion was mitigated by pretreatment of L-NAME. These findings suggest the involvement of $\mathrm{NO}$ in mediating the antisecretory effect of $\mathrm{H}_{2} \mathrm{~S}$.
\end{abstract}

\section{Introduction}

Hydrogen sulfide $\left(\mathrm{H}_{2} \mathrm{~S}\right)$ has been shown to act as a new gaseous transmitter in mammalian tissues $[1,2]$. Three key enzymes, cystathionine- $\gamma$-lyase (CSE), cystathionine- $\beta$ synthase (CBS), and 3-mercaptopyruvate sulfurtransferase (3MST) along with cysteine aminotransferase, are involved in the natural production of $\mathrm{H}_{2} \mathrm{~S}$ in the body [3]. A growing body of literatures have documented several physiological roles for $\mathrm{H}_{2} \mathrm{~S}$ including vasodilation, neuromodulation, and smooth muscle relaxation [4-6]. Additionally, exogenous $\mathrm{H}_{2} \mathrm{~S}$ has been shown to protect the gastric mucosa on different model of experimentally induced gastric ulcer in rats [7-9].

$\mathrm{H}_{2} \mathrm{~S}$ has been shown to increase the release of $\mathrm{NO}$ from vascular endothelium [10]. Moreover, it has been reported that $\mathrm{NaHS}, \mathrm{a}_{2} \mathrm{~S}$ donor, induces the duodenal release of $\mathrm{NO}$ in rat [11]. Since NO has been shown to inhibit gastric acid secretion in rabbit, human and rat [12-14], the present study aimed to elucidate the possible mechanism of the inhibitory effect of $\mathrm{NaHS}$, a $\mathrm{H}_{2} \mathrm{~S}$ donor, on gastric acid secretion in rats and to determine whether this effect is related to nitric oxide.

\section{Materials and Methods}

2.1. Animals. Male Wistar rats $(170-220 \mathrm{~g})$ were supplied from the animal house of Ahvaz Jundishapur University of Medical Sciences. Animals were fed on conventional diets and tap water. They were maintained under standard conditions of humidity, temperature $\left(22 \pm 2^{\circ} \mathrm{C}\right)$, and 
light/dark cycle (12 h: $12 \mathrm{~h}$ ). All experiments were carried out in accordance with ethics committee of Ahvaz Jundishapur University of Medical Sciences (number RDC-9102).

2.2. Animal Grouping and Surgical Procedures. Animals were anesthetized with a mixture of ketamine and xylazine $(60+$ $15 \mathrm{mg} / \mathrm{kg}$, i.p.). Depth of anesthesia was monitored throughout the experiment by the pedal withdrawal (toe pinch) reflex every 30-45 min. If the reflex was observed, a supplemental dose of anesthetics was administered to maintain adequate anesthesia. Animal body temperature was controlled with a rectal thermometer and maintained at $37 \pm 0.5^{\circ} \mathrm{C}$ by using a homeothermic blanket control system (Harvard, Edenbridge, UK). After a midline laparotomy, both the stomach and the duodenum were exposed. A polyethylene catheter $(3 \mathrm{~mm}$, O.D.) was inserted into the stomach through the duodenum and held in place by a ligature around the pylorus. At the beginning of each experiment, the lumen of the stomach was gently rinsed with isotonic saline $\left(\mathrm{pH} 7,37^{\circ} \mathrm{C}\right)$ until gastric washout was clear. In the first set of experiments, forty rats were randomly divided into 5 groups (8 in each). They were control (C), NaHS-, L-NAME + NaHS-, PAG-, and PAG + SNP- (sodium nitroprusside-) treated rats. After determination of the basal acid output, the gastric acid secretion was stimulated by distention $(1.5 \mathrm{~mL} / 100 \mathrm{~g}$ of body weight by normal saline, pH 7 and $37^{\circ} \mathrm{C}$ for $90 \mathrm{~min}$ ) in all groups. In a preliminary study we have shown that NaHS at 20,40, and $80 \mu \mathrm{g} / \mathrm{kg}$ decreases the gastric acid output in a dosedependent manner [15]. Therefore, the maximal affected dose of $\mathrm{NaHS}$ was used in the present work. To evaluate the effect of $\mathrm{H}_{2} \mathrm{~S}$ on distention-induced gastric acid secretion, NaHStreated rats received an intravenous injection of $\mathrm{H}_{2} \mathrm{~S}$ donor, $\mathrm{NaHS}(80 \mu \mathrm{g} / \mathrm{kg})$, via a tail vein just prior to stimulation of the gastric acid secretion by distention. To determine the possible role of $\mathrm{NO}$ in mediating the inhibitory effect of $\mathrm{H}_{2} \mathrm{~S}$ on distention-induced gastric acid secretion, one group of animals, L-NAME + NaHS-treated rats, received $\mathrm{N}^{\mathrm{G}}$-nitroL-arginine methyl ester, L-NAME (10 mg/kg, i.v.), $5 \mathrm{~min}$ before the administration of NaHS $(80 \mu \mathrm{g} / \mathrm{kg}$, i.v.) [11]. To evaluate the effect of endogenous $\mathrm{H}_{2} \mathrm{~S}$ on distention-induced gastric acid secretion, animals in PAG-treated group received cystathionine- $\gamma$-lyase inhibitor, propargylglycine (PAG), at $50 \mathrm{mg} / \mathrm{kg}$, i.v. concomitant with the gastric distention. One group of animals received PAG at $50 \mathrm{mg} / \mathrm{kg}$, i.v. + SNP (a NO donor at $6 \mathrm{mg} / \mathrm{kg}$ intragastrically) [14] concomitant with the gastric distention. At the end of experiment, animals were killed by cardiac exsanguination. Gastric effluents were collected in chilled tubes, centrifuged at $5000 \mathrm{rpm}$ for $10 \mathrm{~min}$, and kept in $-80^{\circ} \mathrm{C}$ until measurement of the luminal levels of NO. In order to measure mRNA expression of endothelial nitric oxide synthase (eNOS), COX-2, and $\mathrm{H}^{+} / \mathrm{K}^{+}$-ATPase $\alpha$-subunit, the stomachs of animals were removed, opened along the greater curvature, rinsed with physiological saline, and pinned out in ice-cold saline. One hundred milligrams of gastric mucosal tissues was quickly excised, snap-frozen, and stored in liquid nitrogen for mRNA analysis. In the second set of experiments, to show the effect of $\mathrm{H}_{2} \mathrm{~S}$ precursor, L-cysteine, on distention-induced gastric acid secretion,
12 rats were randomly divided into L-cysteine-treated and the corresponding control groups (6 in each). They received Lcysteine $(50 \mathrm{mg} / \mathrm{kg}$, i.p.) or saline once a day for 5 days before stimulation of the gastric acid secretion. To quantify the mRNA expressions of eNOS, COX-2, and $\mathrm{H}^{+} / \mathrm{K}^{+}$-ATPase $\alpha$ subunit, $100 \mathrm{mg}$ of gastric mucosa was collected, snap-frozen, and stored in liquid nitrogen.

2.3. Determining the Basal Acid Secretion and Evaluation of Gastric Acid Secretion. After the surgical preparation, basal gastric acid secretion was allowed to stabilize for at least $30 \mathrm{~min}$. At the end of this period, mean acidity of two first 15 min of gastric effluent considered as basal acid output. The acidity in the gastric washout was measured with an autotitrator $\mathrm{pH}$ meter (Radiometer, Copenhagen, Denmark) by automatic potentiometric titration to $\mathrm{pH} 7$ with $0.01 \mathrm{~N}$ $\mathrm{NaOH}$ and was expressed as $\mu \mathrm{EqH}^{+} / 90 \mathrm{~min}$.

2.4. RNA Extraction and cDNA Synthesis. The total RNA was extracted from the frozen tissue samples using TriPure reagent isolation (Roche, Diagnostics). The purity and concentration of the extracted RNA were determined spectrophotometrically at 260 and $280 \mathrm{~nm}$ wavelength (Eppendorf, BioPhotometer Plus, Germany). The cDNA was synthesized from one microgram of the total RNA using a cDNA synthesis kit (Bioneer, Daejeon, South Korea) according to the manufacturer's instruction.

2.5. Quantitative Real-Time PCR. The mRNA levels of the target (eNOS, COX-2, and $\mathrm{H}^{+} / \mathrm{K}^{+}$-ATPase $\alpha$-subunit) and housekeeping genes, glyceraldehyde-3-phosphate dehydrogenase (GAPDH), were measured by quantitative realtime PCR (qPCR) using step-one systems (Applied Biosystems, USA). The specific primers (Bioneer, Daejeon, South Korea) for measurement of eNOS, COX-2, $\mathrm{H}^{+} / \mathrm{K}^{+}$-ATPase $\alpha$ subunit, and GAPDH were used and the lengths for amplified products were as follows: GAPDH (TGCTGGTGCTGAGTATGTCGTG and CGGAGATGATGACCCTTTTGG, $101 \mathrm{bp}$ ), $\mathrm{H}^{+}-\mathrm{K}^{+}$-ATPase $\alpha$-subunit (CCACTAGATCTCTTCTTCAGGAACAGGAT and ACT-ATA-AGC-TTT-TCCGGA-TCT-CAT-CGT-AG, 129 bp), eNOS (TCCGATTCAACAGTGTCTCCT and ACA-GAA-GTG-CGG-GTA-TGC-TC, $251 \mathrm{bp}$ ), and COX-2 (CTCCTCAATACTGGAAACCTAGCACC and TGGTAGGCTGCGGGTCTTG, 144 bp). All PCR amplifications were performed in duplicate reactions and in final volume of $20 \mu \mathrm{L}$ containing $2 \mu \mathrm{L}$ cDNA, $50 \mathrm{~nm}$ of specific primers, and $10 \mu \mathrm{L}$ of Master Mix SYBR Green (2x qPCR Master Mix with SYBR Green I and Rox; Primer design, England) using the following protocol: incubation at $95^{\circ} \mathrm{C}$ for $10 \mathrm{~min}$ to activate DNA Taq polymerase, 40 twostep cycles with $15 \mathrm{~s}$ at $95^{\circ} \mathrm{C}$ for denaturation, and annealingextension at $60^{\circ} \mathrm{C}$ for $1 \mathrm{~min}$. In addition, the no-template negative control $\left(\mathrm{H}_{2} \mathrm{O}\right)$ was routinely run in every PCR. The melting curve was examined at the end of amplification process to ensure the specificity of PCR products. The purity of each amplicon for each reaction was further confirmed by agarose gel electrophoresis. Expression levels of all eNOS and $\mathrm{H}^{+} / \mathrm{K}^{+}$-ATPase $\alpha$-subunit genes were normalized 
against GAPDH expression (internal calibrator for equal RNA template loading and normalization). To determine the relative quantification of gene expression, comparative cycle of threshold (Ct) method with arithmetic formulae $\left(2^{-\Delta \Delta \mathrm{Ct}}\right)$ was used [16]. Expression in control animals was normalized to 1 .

2.6. Determining NO Luminal Level. To show the effect of $\mathrm{NaHS}$ on NO release, the luminal release of NO from the gastric mucosa was measured indirectly based on the amount of $\mathrm{NO}$ metabolites $\left(\mathrm{NO}_{x}\right)$, nitrate $\left(\mathrm{NO}_{2}\right)$, and nitrite $\left(\mathrm{NO}_{3}\right)$ using the nitrate/nitrite colorimetric assay kit purchased from Cayman Chemical Company (Ann Arbor, MI, USA). $\mathrm{NO}_{x}$ levels were measured according to manufacturer's instructions. Briefly, $\mathrm{NO}_{3}$ reduced to $\mathrm{NO}_{2}$ with nitrate reductase and then nitrite was incubated with Griess reagents for $10 \mathrm{~min}$ at room temperature [17]. The absorbance at $540 \mathrm{~nm}$ was then measured using a plate reader (Bio-Rad, 680 microplate reader) and the results were expressed as total $\mathrm{NO}_{x}$ output obtained for 90 min after treatment with NaHS or L-NAME + NaHS.

2.7. Statistical Analysis. Data are shown as mean \pm S.E.M. Statistical analysis was performed by one-way ANOVA and followed by post hoc Tukey's test. Significance was set at a $P<0.05$ level.

\section{Results}

3.1. Effect of NaHS, L-Cysteine, PAG, and PAG + SNP on Distention-Induced Gastric Acid Secretion. As shown in Figure 1, the gastric acid output in response to distention (physiologic saline, $1.5 \mathrm{~mL} / 100 \mathrm{~g}$ of body weight) was significantly decreased by an intravenous injection of NaHS $(80 \mu \mathrm{g} / \mathrm{kg})$ or as compared with the control group $(P<0.01)$. It also can be seen from Figure 1 that the inhibitory effect of NaHS on distention-induced gastric acid secretion was significantly decreased $(P<0.01)$ by the pretreatment of L-NAME (10 mg/kg, i.v.). According to Figure 1, the gastric acid output in response to distention significantly increased in PAG-treated rats as compared with the control group $(P<$ $0.01)$. The acid response to distention in PAG + SNP-treated rats was significantly lower than in PAG-treated animals (Figure 1). The acid output in response to distention was also significantly decreased five days before treatment with Lcysteine as compared with the corresponding control group (Figure 2).

3.2. Effect of NaHS on Luminal Release of NO. The luminal level of NO was higher in NaHS-treated animals than in control and L-NAME + NaHS groups. NO luminal level in PAG-treated rats was lower than in NaHS-treated group. As shown in Figure 3, this level was significantly increased in NaHS-treated rats compared with the control rats and PAGtreated animals.

3.3. Effect of NaHS and L-Cysteine on mRNA Expressions of $\mathrm{H}^{+} / \mathrm{K}^{+}$-ATPase $\alpha$-Subunit, COX-2, and eNOS. According to Figure 4, the gene expression of eNOS was significantly

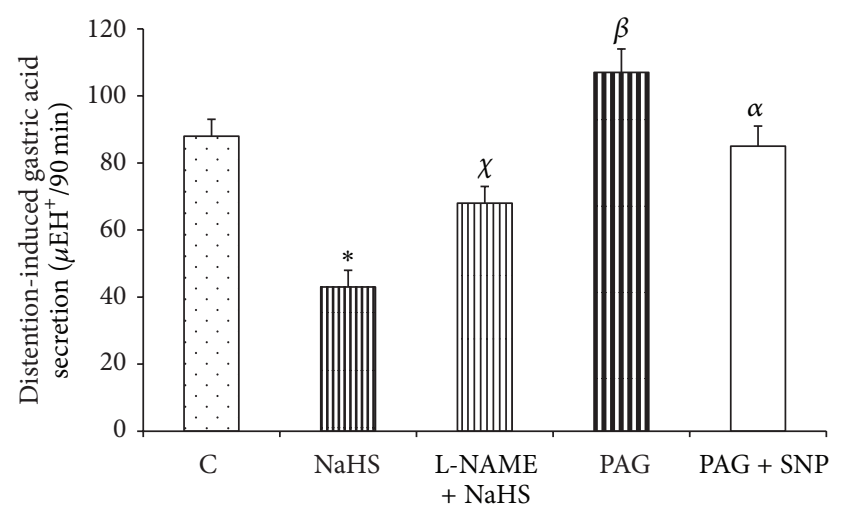

FIGURE 1: NaHS decreased the gastric acid output induced by distention $(1.5 \mathrm{~mL} / 100 \mathrm{~g}$ of body weight by normal saline and $\mathrm{pH}$ 7 and $37^{\circ} \mathrm{C}$ for $\left.90 \mathrm{~min}\right)$. C: control, NaHS: animals received NaHS $(80 \mu \mathrm{g} / \mathrm{kg}$, i.v. $)$ just prior to stimulation of the gastric acid secretion, $\mathrm{NaHS}+$ L-NAME: animals received L-NAME at $10 \mathrm{mg} / \mathrm{kg}$, i.v., $5 \mathrm{~min}$ before the administration of $\mathrm{NaHS}(80 \mu \mathrm{g} / \mathrm{kg}$, i.v.), PAG: rats received cystathionine- $\gamma$-lyase inhibitor, propargylglycine (PAG), at $50 \mathrm{mg} / \mathrm{kg}$, i.v. concomitant with the gastric distention, PAG + SNP: animals received PAG at $50 \mathrm{mg} / \mathrm{kg}$, i.v. + SNP (a NO donor at $6 \mathrm{mg} / \mathrm{kg}$ intragastrically) concomitant with the gastric distention. Asterisk indicates a significant decrease $\left({ }^{*} P<0.01\right)$ as compared to the control group; ${ }^{X}$ in the above column indicates a significant increase $\left({ }^{\chi} P<0.01\right)$ as compared to NaHS-treated group; ${ }^{\alpha} P<$ 0.05 as compared with PAG + SNP group; ${ }^{\beta}$ in the above column indicates a significant increase $\left({ }^{\beta} P<0.01\right)$ as compared to the control. Data are expressed as mean \pm S.E.M.

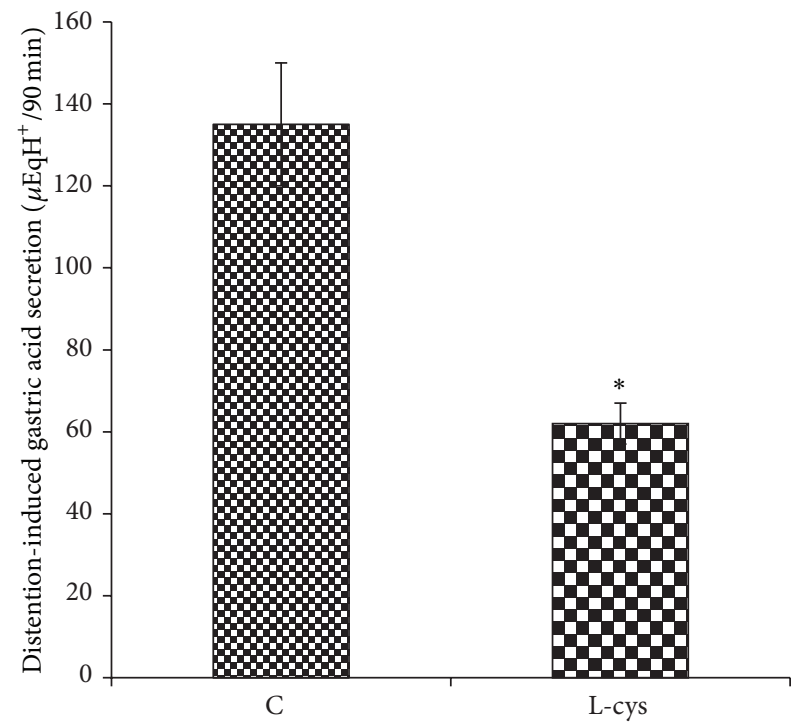

FIGURE 2: L-Cysteine decreased the gastric acid output induced by distention $(1.5 \mathrm{~mL} / 100 \mathrm{~g}$ of body weight by normal saline and $\mathrm{pH} 7$ and $37^{\circ} \mathrm{C}$ for $\left.90 \mathrm{~min}\right)$. Animals received normal saline at $2 \mathrm{~mL} / \mathrm{kg}$, i.p. (C: control), or L-cysteine at $50 \mathrm{mg} / \mathrm{kg}$, i.p. (L-cys), once a day for five days before stimulation of the gastric acid secretion. Asterisk indicates a significant decrease $\left({ }^{*} P<0.01\right)$ as compared to control. Data are expressed as mean \pm S.E.M. 


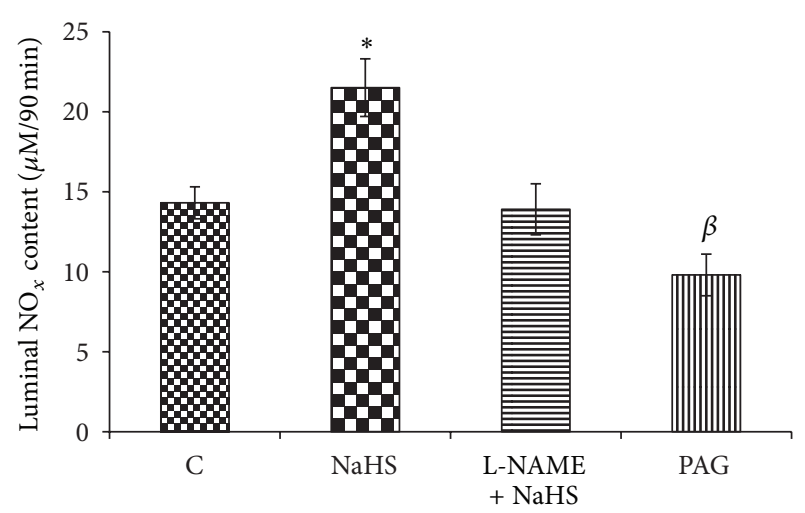

FIgURE 3: Effect of NaHS treatment on luminal level of nitric oxide. The luminal content of NO was significantly increased by NaHS. C: control, NaHS: animals received NaHS $(80 \mu \mathrm{g} / \mathrm{kg}$, i.v.) just prior to stimulation of the gastric acid secretion, NaHS + L-NAME: animals received L-NAME at $10 \mathrm{mg} / \mathrm{kg}$, i.v., $5 \mathrm{~min}$ before the administration of NaHS $(80 \mu \mathrm{g} / \mathrm{kg}$, i.v. $)$, PAG: rats received cystathionine- $\gamma$-lyase inhibitor, propargylglycine (PAG), at $50 \mathrm{mg} / \mathrm{kg}$, i.v. concomitant with the gastric distention. ${ }^{*} P<0.01$ versus the control group; ${ }^{\beta}$ in the above column indicates a significant decrease $\left({ }^{\beta} P<0.01\right)$ as compared to the control. Data are expressed as mean \pm S.E.M.

increased by NaHS and L-cysteine as compared with the corresponding controls. The mRNA expression of eNOS was significantly decreased in PAG-treated rats as compared with the control group (Figure 4). The level of mRNA expression of $\mathrm{H}^{+} / \mathrm{K}^{+}$-ATPase $\alpha$-subunit in control rats was higher than in NaHS- and L-cysteine-treated animals. According to Figure 5, this level was significantly decreased in NaHSand L-cysteine-treated rats compared with the corresponding control groups. In contrast, the mRNA expression of $\mathrm{H}^{+} / \mathrm{K}^{+}$-ATPase $\alpha$-subunit was significantly increased in PAGtreated rats as compared with the control group (Figure 5). According to Figure 6, the gene expression of COX-2 was significantly increased by NaHS and L-cysteine as compared with the corresponding controls.

\section{Discussion}

It has been shown that hydrogen sulfide increases the release of NO from the vascular endothelium [10]. Ise and coworkers also showed that a mucosal administration of NaHS, a $\mathrm{H}_{2} \mathrm{~S}$ donor, increases duodenal release of $\mathrm{NO}$ in rats [11]. Nitric oxide has been shown to modulate the acid output in response to gastric distention [14]. The inhibitory effect of NO on gastric acid secretion is mediated by acting directly on the parietal cell or indirectly by inhibiting the release of histamine [13, 18]. Moreover, NO has been reported to increase somatostatin release from rabbit D cells [19], which in turn decreases histamine release from enterochromaffinlike cells (ECL). Nitric oxide has been also demonstrated to inhibit gastric acid secretion in isolated human gastric glands and there is endogenous formation of $\mathrm{NO}$ within the glandular epithelium in the vicinity of the parietal cells [13].
As shown in the present study, an intravenous injection of $\mathrm{H}_{2} \mathrm{~S}$ donor, NaHS, and five-day pretreatment of $\mathrm{H}_{2} \mathrm{~S}$ precursor, L-cysteine, decreased the acid output in response to gastric distention (Figures 1 and 2). The results also showed the antisecretory effect of $\mathrm{H}_{2} \mathrm{~S}$ significantly reduced by L-NAME pretreatment. Therefore, the inhibitory effect of $\mathrm{H}_{2} \mathrm{~S}$ on gastric acid secretion could partly be mediated through an increase in NO release. To clarify the effect of $\mathrm{H}_{2} \mathrm{~S}$ on NO production and release, we first measured the luminal level of $\mathrm{NO}$ using a nitrate/nitrite colorimetric assay kit. According to Figure 3, NO content in gastric effluents increases after NaHS treatment. The luminal level of NO in NaHS-treated rats was higher than in control animals and also in L-NAME pretreated rats (Figure 3). This level in PAG-treated rats was significantly lower than in NaHStreated and control groups. Recently, Ise et al. demonstrated that the stimulatory effect of NaHS on duodenal bicarbonate secretion decreased by L-NAME pretreatment, suggesting the participation of endogenous NO in this action [11]. Therefore, these findings together clearly showed that endogenous and exogenous $\mathrm{H}_{2} \mathrm{~S}$ stimulate nitric oxide production/release and show the involvement of nitric oxide in this inhibitory effect of hydrogen sulfide on distention-induced gastric acid secretion. Moreover, the results showed that the acid output in response to distention in PAG + SNP-treated rats was significantly lower than in PAG-treated animals, indicating the involvement of $\mathrm{NO}$ in antisecretory effect of $\mathrm{H}_{2} \mathrm{~S}$ (Figure 1).

Secondly, to evaluate the effects of endogenous and exogenous $\mathrm{H}_{2} \mathrm{~S}$ on eNOS gene expression, the mRNA level of eNOS was measured by semiquantitative real-time PCR. As shown in Figure 4(a), gene expression of eNOS in PAGtreated rats was significantly lower than in control rats. This level in NaHS- and L-cysteine-treated rats was significantly increased as compared with the corresponding control rats (Figures 4(a) and 4(b)). These findings show that endogenous and exogenous $\mathrm{H}_{2} \mathrm{~S}$ stimulate eNOS mRNA expression. Thus, the inhibitory effect of $\mathrm{H}_{2} \mathrm{~S}$ on gastric acid secretion is partly mediated through an increase in the gene expression of eNOS and at the same time an increase in NO production/release, resulting in the inhibition of acid secretion.

According to Figure 4, eNOS mRNA expression increased in L-NAME + NaHS-treated animals rats as compared with the control rats while the luminal release of $\mathrm{NO}$ and also gastric acid output did not change compared with the control group. These results show that NaHS upregulated the gene expression of eNOS like NaHS-treated group but it did not affect the enzyme activity and NO production/release as well as the gastric acid output because of the presence of L-NAME.

According to Figure 1, L-NAME pretreatment could not completely reverse the antisecretory effect of $\mathrm{NaHS}$ on distention-induced gastric acid secretion. Therefore, it seems that there is still another factor which is activated by $\mathrm{H}_{2} \mathrm{~S}$ and it in turn inhibits or neutralizes the gastric acid. To answer the above mentioned question, we quantified the gene expression of COX-2. Hydrogen sulfide has been shown to upregulate the gene expression of COX-2 and $\mathrm{PGE}_{2}$ production in isolated rat cardiomyocytes [20]. Moreover, it has been reported that inhibition of $\mathrm{H}_{2} \mathrm{~S}$ production decreases the level of COX-2 


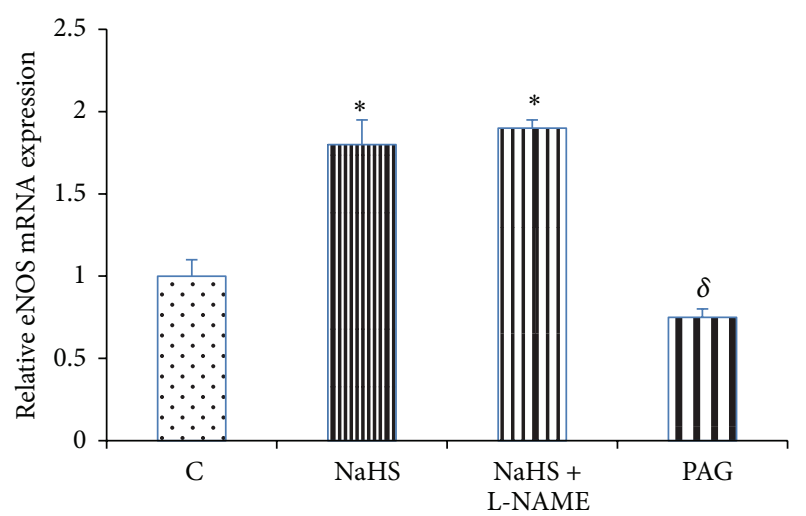

(a)

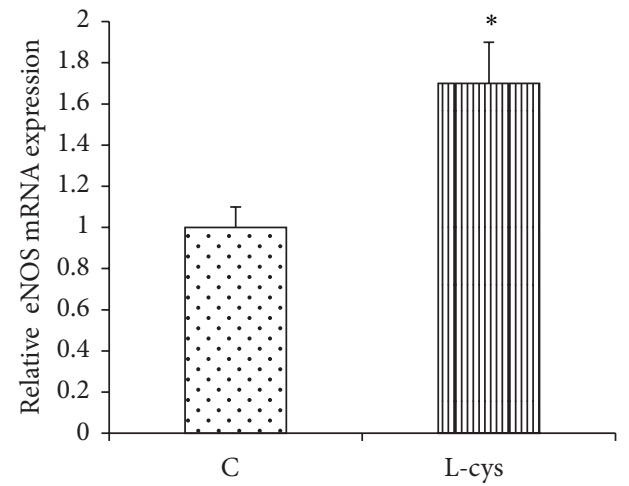

(b)

FIGURE 4: (a) Effect of NaHS on the gastric mucosal mRNA expression of endothelial nitric oxide synthase (eNOS). Analysis of semiquantitative real-time PCR results showed that the administration of NaHS increased the mRNA expression of eNOS. C: control, NaHS: animals received NaHS $(80 \mu \mathrm{g} / \mathrm{kg}$, i.v. ) just prior to stimulation of the gastric acid secretion, NaHS + L-NAME: animals received L-NAME at $10 \mathrm{mg} / \mathrm{kg}$, i.v., $5 \mathrm{~min}$ before the administration of NaHS $(80 \mu \mathrm{g} / \mathrm{kg}$, i.v.), and PAG: rats received cystathionine- $\gamma$-lyase inhibitor, propargylglycine (PAG), at $50 \mathrm{mg} / \mathrm{kg}$, i.v. concomitant with the gastric distention. (b) animals received normal saline at $2 \mathrm{~mL} / \mathrm{kg}$, i.p. (C: control), or L-cysteine at $50 \mathrm{mg} / \mathrm{kg}$, i.p. (L-cys), once a day for five days before stimulation of the gastric acid secretion. Asterisks indicate a significant increase $\left({ }^{*} \mathrm{P}<0.01\right)$ as compared to the control group; ${ }^{\delta} \mathrm{P}<0.05$ indicates a significant decrease as compared with the control group. Data are expressed as mean \pm S.E.M.

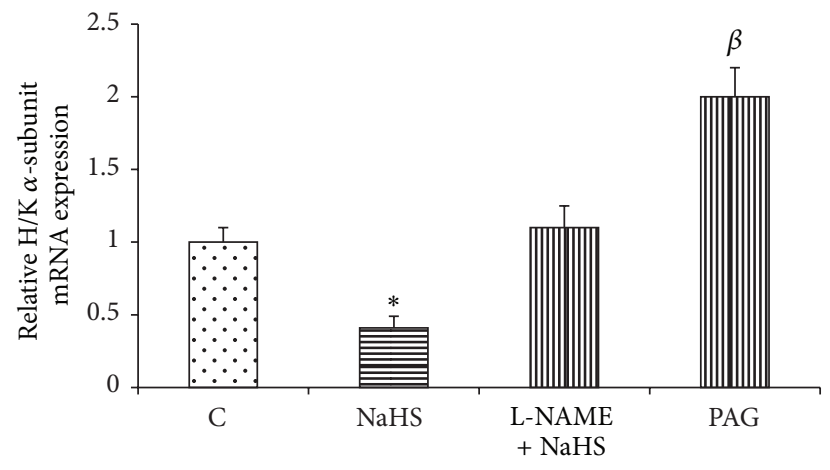

(a)

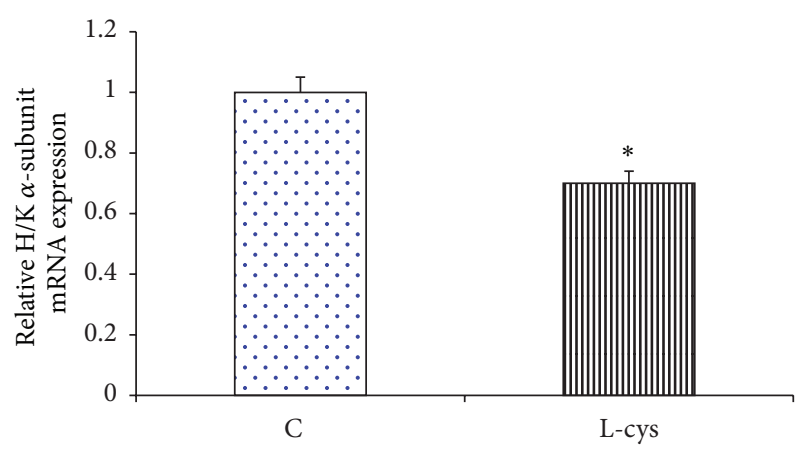

(b)

FIGURE 5: Effect of NaHS (a) and L-cysteine (b) on the gastric mucosal mRNA expression of $\mathrm{H}^{+} / \mathrm{K}^{+}$-ATPase $\alpha$-subunit. (a) Analysis of semiquantitative real-time PCR results showed that the administration of NaHS decreased the mRNA expression of $\mathrm{H}^{+} / \mathrm{K}^{+}-\mathrm{ATPase} \alpha$-subunit. In contrast, this level increased in PAG-treated rats as compared to the control group. C: control, NaHS: animals received NaHS $(80 \mu \mathrm{g} / \mathrm{kg}$, i.v.) just prior to stimulation of the gastric acid secretion, NaHS + L-NAME: animals received L-NAME at $10 \mathrm{mg} / \mathrm{kg}$, i.v., $5 \mathrm{~min}$ before the administration of NaHS ( $80 \mu \mathrm{g} / \mathrm{kg}$, i.v.), and PAG: rats received cystathionine- $\gamma$-lyase inhibitor, propargylglycine (PAG), at $50 \mathrm{mg} / \mathrm{kg}$, i.v. concomitant with the gastric distention. (b) Animals received normal saline at $2 \mathrm{~mL} / \mathrm{kg}$, i.p. (C: control), or L-cysteine at $50 \mathrm{mg} / \mathrm{kg}$, i.p. (Lcys), once a day for five days before stimulation of the gastric acid secretion. Asterisks indicate a significant decrease $\left({ }^{*} P<0.01\right)$ as compared to the control group; ${ }^{\beta}$ in the above column indicates a significant increase $\left({ }^{\beta} P<0.01\right)$ as compared to the control. Data are expressed as mean \pm S.E.M.

expression and $\mathrm{PGE}_{2}$ synthesis in the rat colon [21]. It has been shown that the protective activity of $\mathrm{H}_{2} \mathrm{~S}$ on ethanolinduced gastric lesions in mice is dependent on the activation of capsaicin-sensitive sensory neurons [22]. Capsaicin has been demonstrated to increase $\mathrm{PGE}_{2}$ production and $\mathrm{NO}$ release in the duodenum via the activation of these sensory neurons $[23,24]$. Consistent with these results, the findings of present study showed that the mRNA expression of COX2 in gastric mucosal tissue was upregulated in NaHS- and Lcysteine-treated rats as compared with the control (Figure 6) while it significantly decreased in PAG-treated animals. These findings together show that exogenous and endogenous $\mathrm{H}_{2} \mathrm{~S}$ increase the prostaglandins production/release. Therefore, due to the antisecretory and acid-neutralizing properties of PGs, it could conclude that a reduction of the acid output/an increase in gastric $\mathrm{pH}$ by NaHS in response to distention is partly mediated through an increase in the PGs production.

Sodium nitroprusside, a NO donor, has been shown to decrease the activity of gastric $\mathrm{H}^{+}-\mathrm{K}^{+}$-ATPase in rats [25]. Our findings also showed that an intravenous injection 


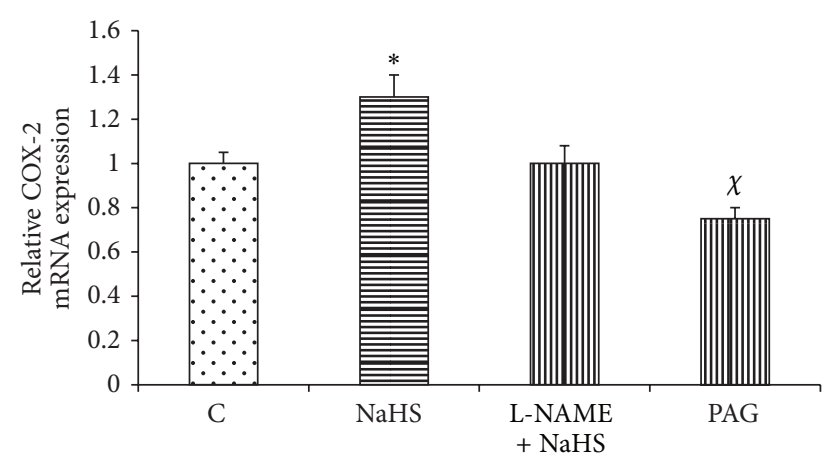

(a)

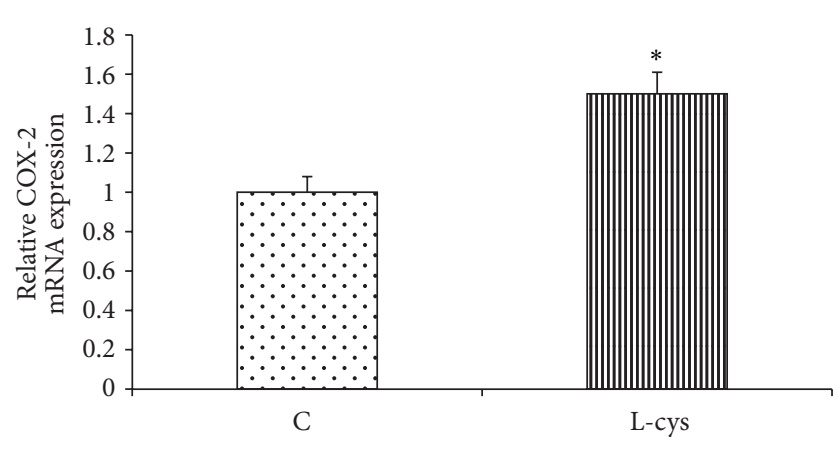

(b)

FIGURE 6: Effect of NaHS (a) and L-cysteine (b) on the gastric mucosal mRNA expression of COX-2. (a) Analysis of semiquantitative real-time PCR results showed that the administration of NaHS increased the mRNA expression of COX-2. C: control, NaHS: animals received NaHS $(80 \mu \mathrm{g} / \mathrm{kg}$, i.v. $)$ just prior to stimulation of the gastric acid secretion, NaHS + L-NAME: animals received L-NAME at $10 \mathrm{mg} / \mathrm{kg}$, i.v., $5 \mathrm{~min}$ before the administration of NaHS ( $80 \mu \mathrm{g} / \mathrm{kg}$, i.v.), and PAG: rats received cystathionine- $\gamma$-lyase inhibitor, propargylglycine (PAG), at $50 \mathrm{mg} / \mathrm{kg}$, i.v. concomitant with the gastric distention. (b) Animals received normal saline at $2 \mathrm{~mL} / \mathrm{kg}$, i.p. (C: control), or L-cysteine at $50 \mathrm{mg} / \mathrm{kg}$, i.p. (Lcys), once a day for five days before stimulation of the gastric acid secretion. Asterisks indicate a significant increase $\left({ }^{*} P<0.01\right)$ as compared to the control group; ${ }^{\chi} P<0.05$ indicates a significant decrease as compared with the control. Data are expressed as mean \pm S.E.M.

of NaHS and five-day L-cysteine pretreatment significantly decreased mRNA expression of $\mathrm{H}^{+} / \mathrm{K}^{+}$-ATPase $\alpha$-subunit in NaHS-treated rats compared with the corresponding control groups (Figures 5(a) and 5(b)). According to Figure 5, the inhibitory effect of NaHS on mRNA expression of $\mathrm{H}^{+} / \mathrm{K}^{+}$ATPase was abolished by L-NAME pretreatment, suggesting the involvement of NO. Therefore, these results suggest that the other possible antisecretory mechanism of NaHS on gastric acid secretion might be mediated by reducing mRNA expression of $\mathrm{H}^{+} / \mathrm{K}^{+}$-ATPase $\alpha$-subunit.

What is the clinical implication? Recently, there is a growing body of text that has been demonstrated by $\mathrm{H}_{2} \mathrm{~S}$ that acts as a rescue molecule for mucosal defense. Till now the mechanisms underlying the gastroprotective effects of hydrogen sulfide were attributed to maintenance and/or elevation of gastric mucosal blood flow [7], stimulation of bicarbonate secretion [11], reduction of proinflammatory cytokine expression/release $[9,26]$, increase of prostaglandin synthesis [19], decrease of reactive oxygen metabolite production [21], and enhancement of tissue repair $[8,27]$. The findings of the present study showed that the antisecretory effect of $\mathrm{H}_{2} \mathrm{~S}$ could be the other possible protective mechanism.

What is the physiologic role of endogenous $\mathrm{H}_{2} \mathrm{~S}$ in regulation of gastric acid secretion? The enzyme activity and mRNA expression of CSE have been shown in the rat stomach [28]. Recently, we have shown that pharmacological inhibition of CSE by preadministration of PAG leads to an increase in the gastric acid output in response to distention compared to corresponding control [15]. As shown in Figure 1, the results of present study were also confirmed by the previous findings that suggest that the CSE activity and $\mathrm{H}_{2} \mathrm{~S}$ production increase concomitant of gastric acid stimulation and decrease the acid output in response to gastric distention. According to Figure 5, mRNA expression of $\mathrm{H}^{+} / \mathrm{K}^{+}$-ATPase $\alpha$-subunit in PAG-treated rats significantly increased as compared to control group. The results together suggest that, concomitant with stimulation of the gastric acid secretion, the CSE activity and $\mathrm{H}_{2} \mathrm{~S}$ production/release increase and subsequently decrease mRNA expression of $\mathrm{H}^{+} / \mathrm{K}^{+}$-ATPase $\alpha$-subunit (Figures 1 and 5 ). These results suggest a housekeeping role for $\mathrm{H}_{2} \mathrm{~S}$ to maintain the gastric mucosal integrity by inducing bicarbonate secretion as shown by the previous studies [11] and at the same time by reducing the gastric acid output as shown by the current study.

Moreover, the endogenous $\mathrm{H}_{2} \mathrm{~S}$ has been shown to excite the contraction of gastric smooth muscles in mouse and guinea-pig $[29,30]$. Therefore, the results of the present study along with the previous reports about the effect of $\mathrm{H}_{2} \mathrm{~S}$ on gastric mucosal defense as well as on gastric motility provide new concepts from the physiologic role of $\mathrm{H}_{2} \mathrm{~S}$ in the stomach.

The results of the present study clearly showed that an increase in $\mathrm{NO}$ concentration and prostaglandins release resulted from the administration of NaHS inhibited and neutralize the gastric acid output. The findings also suggest that $\mathrm{H}_{2} \mathrm{~S}$ exerts both an antisecretory effect by reducing the acid output as shown by the present work and at the same time an antacid activity by inducing bicarbonate production as shown by the previous reports [11].

In conclusion the present study showed the following. (i) Administration of NaHS, a $\mathrm{H}_{2} \mathrm{~S}$ donor, and L-cysteine, $\mathrm{H}_{2} \mathrm{~S}$ precursor, reduced the acid output in response to gastric distention. (ii) Pretreatment with L-NAME mitigated the inhibitory effect of NaHS on distention-induced gastric acid secretion. (iii) The mRNA level of eNOS and COX-2 was significantly increased by NaHS and L-cysteine. (iv) The gene expression of $\mathrm{H}^{+} / \mathrm{K}^{+}$-ATPase $\alpha$-subunit was significantly decreased by NaHS and L-cysteine. (v) The luminal level of nitric oxide was increased by $\mathrm{NaHS}$.

\section{Conflict of Interests}

The authors declare that there is no conflict of interests regarding the publication of this paper. 


\section{Acknowledgment}

The authors are thankful to Vice Chancellor of Research Affairs of Ahvaz Jundishapur University of Medical Sciences for financial support (Grant no. RDC-9102).

\section{References}

[1] P. K. Moore, M. Bhatia, and S. Moochhala, "Hydrogen sulfide: from the smell of the past to the mediator of the future?" Trends in Pharmacological Sciences, vol. 24, no. 12, pp. 609-611, 2003.

[2] R. Wang, "Two's company, three's a crowd: can $\mathrm{H}_{2} \mathrm{~S}$ be the third endogenous gaseous transmitter?" FASEB Journal, vol. 16, no. 13, pp. 1792-1798, 2002.

[3] H. Kimura, "Hydrogen sulfide: its production, release and functions," Amino Acids, vol. 41, no. 1, pp. 113-121, 2011.

[4] W. Zhao, J. Zhang, Y. Lu, and R. Wang, "The vasorelaxant effect of $\mathrm{H}_{2} \mathrm{~S}$ as a novel endogenous gaseous KATP channel opener," The EMBO Journal, vol. 20, no. 21, pp. 6008-6016, 2001.

[5] H. Kimura, "Hydrogen sulfide as a neuromodulator," Molecular Neurobiology, vol. 26, no. 1, pp. 13-19, 2002.

[6] R. Hosoki, N. Matsuki, and H. Kimura, "The possible role of hydrogen sulfide as an endogenous smooth muscle relaxant in synergy with nitric oxide," Biochemical and Biophysical Research Communications, vol. 237, no. 3, pp. 527-531, 1997.

[7] S. Fiorucci, E. Antonelli, E. Distrutti et al., "Inhibition of hydrogen sulfide generation contributes to gastric injury caused by anti-inflammatory nonsteroidal drugs," Gastroenterology, vol. 129, no. 4, pp. 1210-1224, 2005.

[8] J. L. Wallace, M. Dicay, W. McKnight, and G. R. Martin, "Hydrogen sulfide enhances ulcer healing in rats," FASEB Journal, vol. 21, no. 14, pp. 4070-4076, 2007.

[9] S. A. Mard, N. Neisi, G. Solgi, M. Hassanpour, M. Darbor, and M. Maleki, "Gastroprotective effect of NAHS against mucosal lesions induced by ischemia-reperfusion injury in rat," Digestive Diseases and Sciences, vol. 57, no. 6, pp. 1496-1503, 2012.

[10] W. Zhao and R. Wang, " $\mathrm{H}_{2} \mathrm{~S}$-induced vasorelaxation and underlying cellular and molecular mechanisms," The American Journal of Physiology: Heart and Circulatory Physiology, vol. 283, no. 2, pp. H474-H480, 2002.

[11] F. Ise, H. Takasuka, S. Hayashi et al., "Stimulation of duodenal $\mathrm{HCO}^{-}$secretion by hydrogen sulphide in rats: Relation to prostaglandins, nitric oxide and sensory neurones," Acta Physiologica, vol. 201, no. 1, pp. 117-126, 2011.

[12] H. Kim and K. H. Kim, "Effects of a nitric oxide donor and nitric oxide synthase inhibitors on acid secretion of isolated rabbit gastric glands," Pharmacology, vol. 53, no. 6, pp. 331-339, 1996.

[13] A. Berg, S. Redeen, A.-C. Ericson, and S. E. Sjöstrand, "Nitric oxide-an endogenous inhibitor of gastric acid secretion in isolated human gastric glands," BMC Gastroenterology, vol. 4, article 16, 2004.

[14] S. Kato, M. Kitamura, R. P. Korolkiewicz, and K. Takeuchi, "Role of nitric oxide in regulation of gastric acid secretion in rats: effects of NO donors and NO synthase inhibitor," British Journal of Pharmacology, vol. 123, no. 5, pp. 839-846, 1998.

[15] S. A. Mard, M. Maleki, M. K. Gharib Naseri, and A. H. Saberi, "Effects of endogenous production and exogenous administration of $\mathrm{H}_{2} \mathrm{~S}$ on gastric acid secretion in rats," The Journal of Physiology and Pharmacology, vol. 15, no. 4, pp. 499-506, 2011.

[16] K. J. Livak and T. D. Schmittgen, "Analysis of relative gene expression data using real-time quantitative PCR and the 2$\Delta \Delta$ CT method," Methods, vol. 25, no. 4, pp. 402-408, 2001.
[17] L. C. Green, D. A. Wagner, and J. Glogowski, "Analysis of nitrate, nitrite, and ${ }^{15} \mathrm{~N}$ nitrate in biological fluids," Analytical Biochemistry, vol. 126, no. 1, pp. 131-138, 1982.

[18] A. Berg, S. Kechagias, S. E. Sjöstrand, and A.-C. Ericson, "Morphological support for paracrine inhibition of gastric acid secretion by nitric oxide in humans," Scandinavian Journal of Gastroenterology, vol. 36, no. 10, pp. 1016-1021, 2001.

[19] N. Arebi, Z. V. Healey, P. W. Bliss et al., "Nitric oxide regulates the release of somatostatin from cultured gastric rabbit primary D-cells," Gastroenterology, vol. 123, no. 2, pp. 566-576, 2002.

[20] L.-F. Hu, T.-T. Pan, K. L. Neo, Q. C. Yong, and J.-S. Bian, "Cyclooxygenase-2 mediates the delayed cardioprotection induced by hydrogen sulfide preconditioning in isolated rat cardiomyocytes," Pflugers Archiv European Journal of Physiology, vol. 455, no. 6, pp. 971-978, 2008.

[21] J. L. Wallace, L. Vong, W. McKnight, M. Dicay, and G. R. Martin, "Endogenous and exogenous hydrogen sulfide promotes resolution of colitis in rats," Gastroenterology, vol. 137, no. 2, pp. 569.el578.e1, 2009.

[22] J. V. R. Medeiros, V. H. Bezerra, A. S. Gomes et al., "Hydrogen sulfide prevents ethanol-induced gastric damage in mice: role of ATP-sensitive potassium channels and capsaicin-sensitive primary afferent neurons," Journal of Pharmacology and Experimental Therapeutics, vol. 330, no. 3, pp. 764-770, 2009.

[23] E. Aihara, S. Kagawa, M. Hayashi, and K. Takeuchi, "Ace inhibitor and AT1 antagonist stimulate duodenal $\mathrm{HCO}^{-}$secretion mediated by a common pathway-involvement of PG, NO and bradykinin," Journal of Physiology and Pharmacology, vol. 56, no. 3, pp. 391-406, 2005.

[24] S. Kagawa, M. Aoi, Y. Kubo, T. Kotani, and K. Takeuchi, "Stimulation by capsaicin of duodenal $\mathrm{HCO}^{-}$secretion via afferent neurons and vanilloid receptors in rats: comparison with acid-induced $\mathrm{HCO}^{-}$response," Digestive Diseases and Sciences, vol. 48, no. 9, pp. 1850-1856, 2003.

[25] R. Bulut, Y. Ünlüçerçi, S. Bekpinar, and L. Kuntsal, "Nitric oxide-mediated regulation of gastric $\mathrm{H}+, \mathrm{K}+$-ATPase and alcohol dehydrogenase following ethanol-induced injury in rats," Digestive Diseases and Sciences, vol. 44, no. 7, pp. 1417-1422, 1999.

[26] L. Li, G. Rossoni, A. Sparatore, L. C. Lee, P. Del Soldato, and P. K. Moore, "Anti-inflammatory and gastrointestinal effects of a novel diclofenac derivative," Free Radical Biology and Medicine, vol. 42, no. 5, pp. 706-719, 2007.

[27] C. Szabó and A. Papapetropoulos, "Hydrogen sulphide and angiogenesis: mechanisms and applications," British Journal of Pharmacology, vol. 164, no. 3, pp. 853-865, 2011.

[28] S. Fiorucci, E. Distrutti, G. Cirino, and J. L. Wallace, "The emerging roles of hydrogen sulfide in the gastrointestinal tract and liver," Gastroenterology, vol. 131, no. 1, pp. 259-271, 2006.

[29] P. Zhao, X. Huang, Z.-Y. Wang et al., "Dual effect of exogenous hydrogen sulfide on the spontaneous contraction of gastric smooth muscle in guinea-pig," European Journal of Pharmacology, vol. 616, no. 1-3, pp. 223-228, 2009.

[30] Y.-F. Han, X. Huang, X. Guo et al., "Evidence that endogenous hydrogen sulfide exerts an excitatory effect on gastric motility in mice," European Journal of Pharmacology, vol. 673, no. 1-3, pp. 85-95, 2011. 


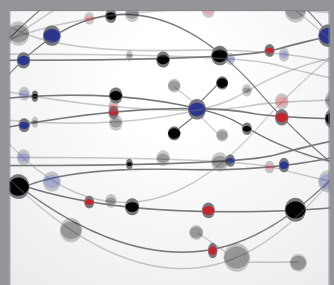

The Scientific World Journal
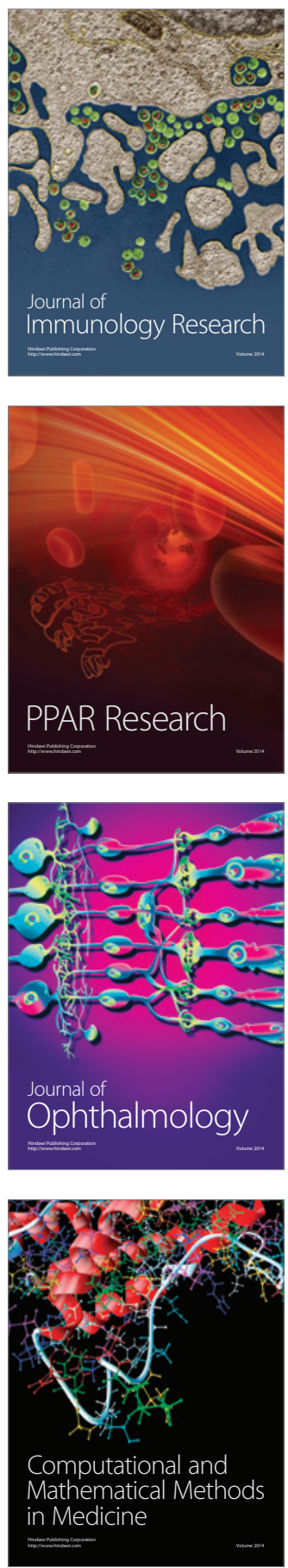

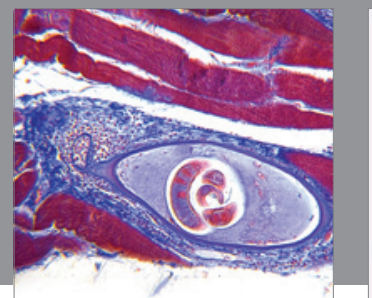

Gastroenterology

Research and Practice
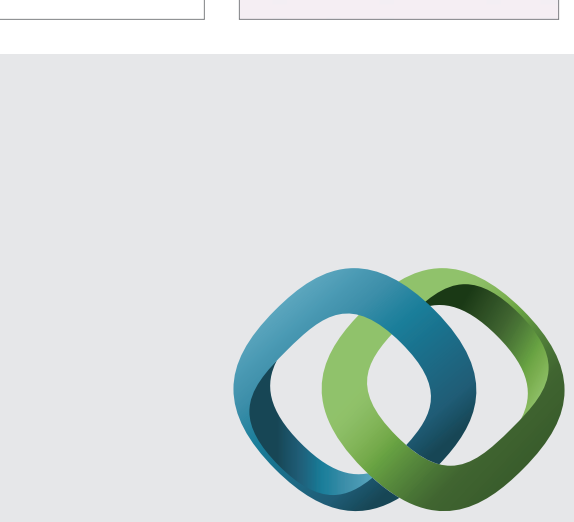

\section{Hindawi}

Submit your manuscripts at

http://www.hindawi.com
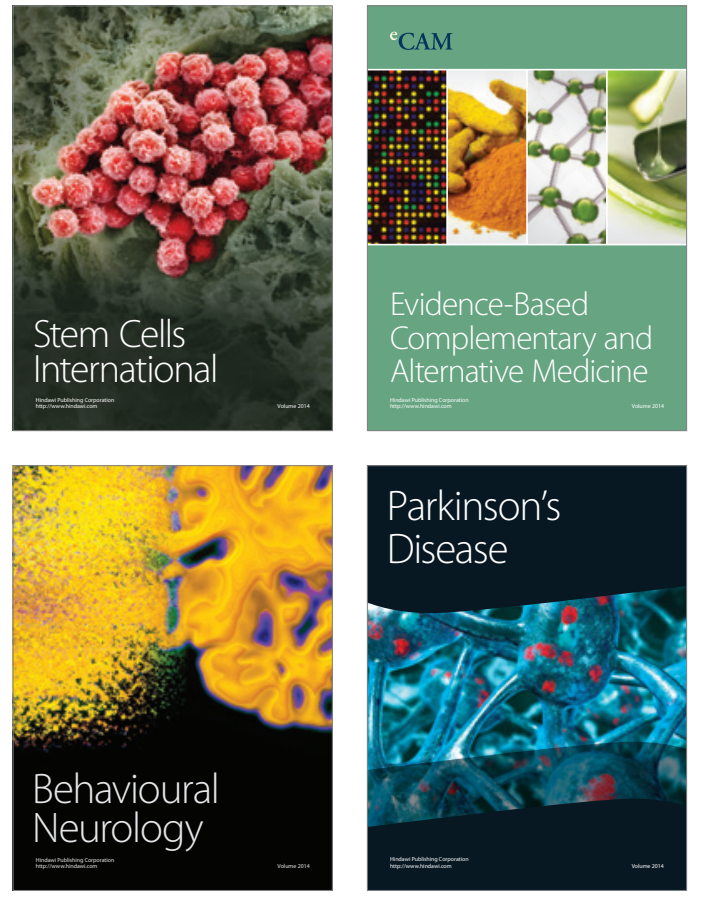
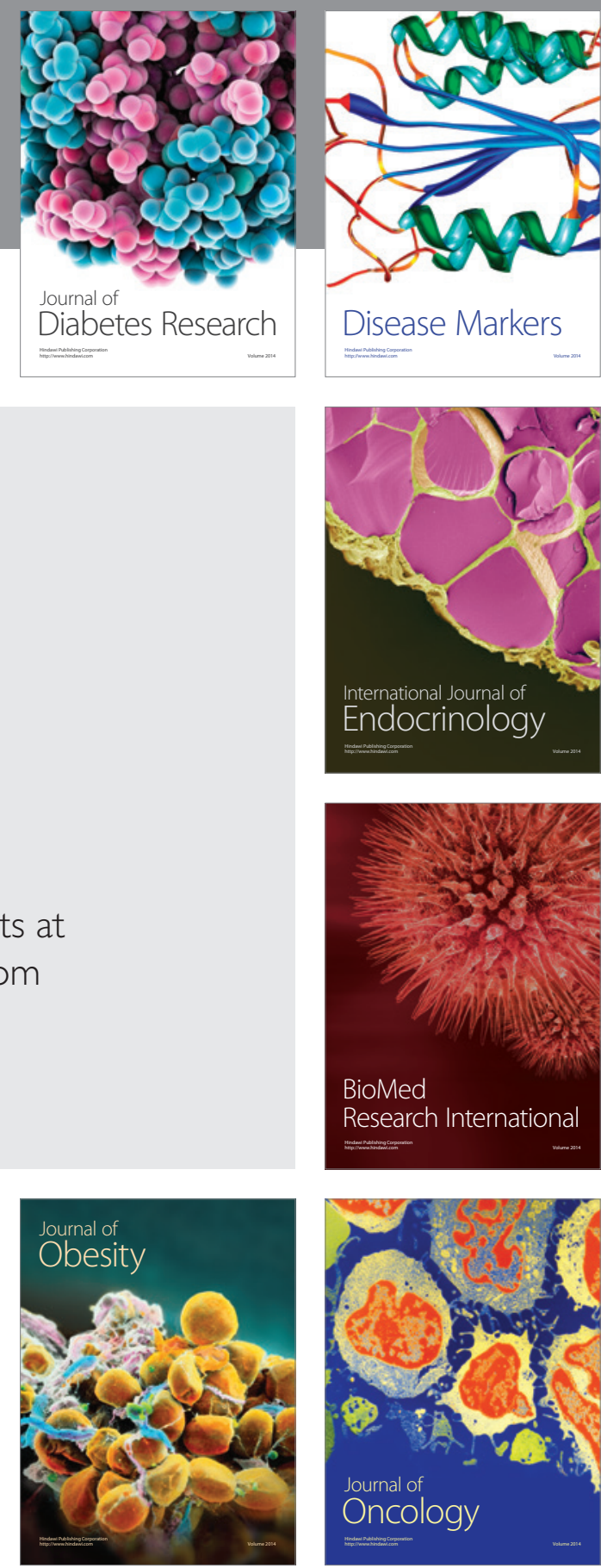

Disease Markers
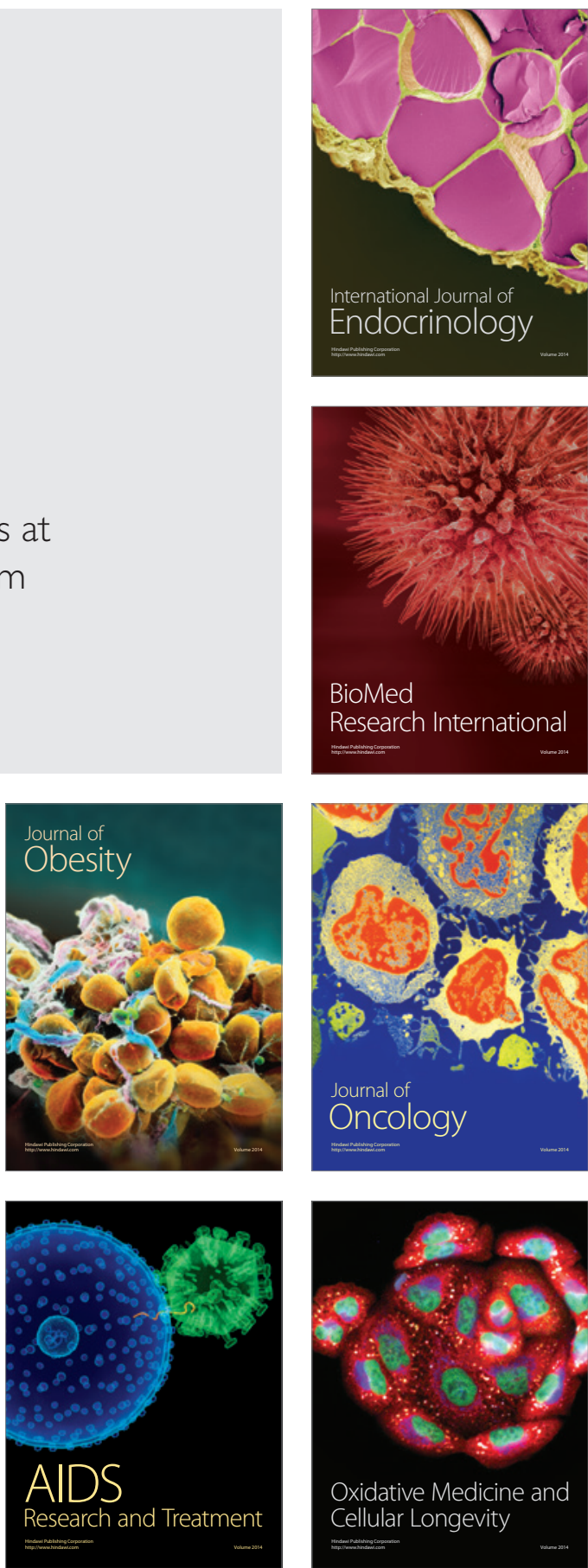